Евгений Викторович Каблуков - кандидат филологических наук, доцент кафедры русского языка и стилистики факультета журналистики Уральского федерального университета имени первого Президента России Б.Н. Ельцина (Екатеринбург, Россия).

e-mail: evgeny.kablukov@urfu.ru

Manuscript received: 05/10/2019 Accepted for publication: 09/20/2019

DOI:

\title{
ON THE DISCURSIVE-PRAGMATIC PROPERTIES OF CONCESSION IN INFORMAL INTERVIEW
}

\author{
Elena Nikolaevna Klemenova \\ Doctor of Philological Sciences, Professor \\ Rostov State University of Economics (RINE) \\ (Russia, Rostov on Don) \\ klemenova@yandex.ru \\ Nadezhda Vladimirovna Kovalchuk \\ PhD, Associate Professor \\ Don State Technical University \\ (Russia, Rostov on Don) \\ nadezhda kovalchuk2012@mail.ru
}

\begin{abstract}
The purpose of this article is to implement a structural and pragmatic analysis of the rhetorical relations of concession in the texts of informal interviews, as well as to identify the basic model of implementation of these relations and its variants. At the level of informal interviews basic model is a three-part sequence of verbal steps of the interlocutors: the speaker, the subject pushes a value judgment $(\mathrm{X})$, and the addressee agrees with this judgment or makes an assignment in favor of its efficacy ( $\mathrm{X}^{\prime}$ ), but also potentially puts forward a contrasting argument $(\mathrm{Y})$. This model has several variations, suggesting a different order of these dialogic steps. The basic implementation model of rhetorical relations concessions and its variants assume the source is equal to the weight of the two potentially incompatible perspectives. Informal interview takes a strong position in popular publications, reflecting the current trends in fashion, cinema, sports, everyday life.
\end{abstract}

Keywords: informal interview, basic model and its variants, concession, communication

\section{О ДИСКУРСИВНО-ПРАГМАТИЧЕСКИХ СВОЙСТВАХ УСТУПКИ В НЕФОРМАЛЬНОМ ИНТЕРВЬЮ}

\author{
Елена Николаевна Клеменова \\ Доктор филологических наук, профессор \\ Ростовский государственный университет экономики \\ (Ростов-на Дону, Россия) \\ e-mail: klemenova@yandex.ru \\ Надежда Владимировна Ковальчук \\ Кандидат филологических наук, доцент \\ Донской государственный технический университет \\ (Ростов-на Дону, Россия) \\ e-mail: nadezhda_kovalchuk_2012@mail.ru
}

\begin{abstract}
Аннотация. Целью данной статьи является осуществление структурно-прагматического анализа риторических отношений уступки в текстах неформальных интервью, а также выявление базовой модели реализации этих отношений и ее вариантов. На уровне неформального интервью базовой моделью является трехчастная последовательность вербальных шагов собеседников: говорящий, субъект выдвигает ценностное суждение (X), а адресат соглашается с этим суждением или делает уступку в пользу его эффективности (X'), но также потенциально выдвигает контрастный аргумент (Y). Эта модель имеет несколько вариаций, предполагающих различный порядок этих диалогических шагов. Базовая модель реализации риторических отношений и ее варианты предполагают, что источник равен весу двух потенциально несовместимых точек зрения. Неформальное интервью занимает прочные позиции в популярных изданиях, отражая современные тенденции в моде, кино, спорте, повседневной жизни.
\end{abstract}

Ключевые слова: неформальное интервью, базовая модель и ее варианты, уступка, взаимодействие 
ВВЕДЕНИЕ. В современных дискурсивно-прагматических исследованиях неформальное интервью интерпретируется как последовательность речевых шагов, реализуемая посредством языковых средств и обладающая определенным воздействием на характер взаимодействия между двумя субъектами, попеременно меняющимися коммуникативными ролями говорящего и слушающего (Azarova, 2013; Vartanova, 2006; Shishkina, 2010). При этом речевой шаг реализует то или иное пропозициональное содержание и выполняет функцию, предопределяемую типом манифестируемого иллокутивного действия. В результате анализа речевых шагов собеседников выявляютсятипы моделей успешной коммуникации.

Прагматическое измерение в неформальном интервью, согласно нашим наблюдениям, способствуют симфонии общения: (1) признание смысловой позиции партнера по взаимодействию и (2) одновременное утверждение собственной точки зрения на обсуждаемую проблему. В результате открывается перспектива моделирования диалогического взаимодействия с учетом того, как можно объяснить речевое поведение интервьюера и респондента в терминах их ментальных состояний и социальных обязательств, обмена актуальной информацией.

Особым аспектом изучения является то, как интервьюер и респондент конструируют отношения коммуникации в тексте неформального интервью, какие прагматические сигналы оказываются доступными им в процессе переработки данного текста.

ОБЗОР ЛИТЕРАТУРЫ.Материалом исследования послужили неформальные интервью, опубликованные в англоязычных периодических изданиях, которые специализируются на разноаспектном освещении мнений ярких представителей кино, телевидения, моды и художественного творчества, а также отражении точек зрения рядовых представителей разнообразных социокультурных сообществ: «Cleo», «Chat», «Country Weekly», «Esquire», «Soap Opera», «Vanity Fair» и др. (2014-2015 гг.). Фрагменты текстов неформального интервью были отобраны методом сплошной выборки.

МЕТОДЫ ИССЛЕДОВАНИЯ. Общефилософские перспективы методологии исследования основываются на философских положениях Ф. де Соссюра и Н.Хомского о разграничении «языка как абстрактного явления» и «языка в действии» с опорой на такие категории, как «язык и речь» (Soussure, 1999), «компетенция и компетентность» (Chomsky, 1972), которые, в свою очередь, соответствуют разграничению эмпирических и рациональных подходов к сбору и анализу языковых данных в аспекте прагматической лингвистики; П.-М. Штраус и В. Минкера в вопросах межличностной коммуникации, которая строится по определенным моделям: «...в процессе обмена диалогическими репликами собеседники попеременно принимают на себя роли говорящего субъекта и адресата, комбинируют речевые шаги в составе реализуемых высказываний для достижения определённых целей» (Strauss, 2010: 28); У. Манна и С. Томпсон о тексте как иерархически формируемом феномене: элементарные текстовые единицы связываются с другими единицами в соответствии с определенными риторическими отношениями, которые отражают текущие намерения говорящего и коммуникативные цели порождаемого текста (Mann 1988).

РЕЗУЛЬТАТЫ И ДИСКУССИЯ. Цель исследования состояла в описании базовой модели риторических отношений уступки в речи участников неформального интервью.

В результате наших наблюдений мы определили, что на уровне неформального интервью базовая модель представляет собой трехчастную последовательность речевых шагов собеседников: говорящий субъект выдвигает некоторое оценочное суждение $(\mathbf{X})$, а адресат соглашается с этим суждением или делает уступку в пользу его действенности (X'), но одновременно выдвигает потенциально контрастирующий аргумент (Y). Эта модель, как было выявлено нами в ходе анализа, обладает несколькими вариациями, предполагающими, в частности, различный порядок следования указанных диалогических шагов, неявное выражение диалогического шага (Y). Ср.:

“-As far as I understand, roles without complexity just don't interest you.

- Except Scully, which I don't see as being particularly complex.

- Yes, but I'm saying, is like you know, as much as your Scully continues to represent an iconic female presence in TV. She's outspoken, powerfull. Your other roles reflect strong women who overcome major obstacles" (Soap World, 2015 , № 16, p. 23).

- «Насколько я понимаю, роли, которые не предполагают сложностей, не интересуют Вас.

- За исключением Скалли, которую я не рассматриваю как особенно сложную.

- Да, но, похоже, Вы знаете о чем я говорю, поскольку Ваша Скалли продолжает репрезентировать знаковое присутствие женского начала на телевидении. Она откровенна, сильна. Ваши другие роли отражают образы сильных женщин, которые преодолевают значительные препятствия».

В анализируемом примере уступительная семантика актуализуется в тот момент спонтанной беседы, когда реагирующий собеседник (актриса Джиллиан Андерсон) указывает, что роль Скалли не оказалась для нее такой уж сложной, как другие исполненные ею роли. Далее интервьюер признает, что в той информации, которую только что представила Дж.Андерсон, есть рациональное зерно, и снова выдвигает суждение относительно того, что все роли, исполняемые актрисой, отличаются сложностью, поскольку отражают характеры сильных женщин, преодолевающих жизненные трудности. С интеракциональной точки зрения признание утверждения, выдвинутого интервьюером, дает возможность реагирующему собеседнику выразить частичное (смягченное) несогласие с этим утверждением.

Базовая модель реализации риторических отношений уступки и ее варианты задействуются респондентом в целях предотвращения несогласия со стороны интервьюера, порождения смыслового унисона посредством признания одновременного существования двух потенциально несовместимых точек зрения. Варианты данной 
модели предоставляют респонденту возможность отступить от предварительно выраженного мнения или усилить контраргумент в пользу своего альтернативного мнения, а не уступку в пользу мнения интервьюера.Ср.:

“(X) - ... but even the privately owned places here are so characterless. I mean by and large.

( $\left.X^{\prime}\right)$ Outside the Village they are.

- You know...

(Y) - There's some in the Village that are nice.

- Outside of the Village, yes. You certainly won't like to lose them. But everywhere else, you know, they're all alikechrome and black chairs...

- And all those pictures and so forth...

- Yes, they're obvious not places where they want you to linger..." (CountryWeekly 2015, Nov., 18, p. 32).

«(X)- ... но даже местечки, находящиеся в частной собственности, здесь такие безликие. Я имею в виду по большому счету.

(X') Они находятся вне района Вилладж.

- Знаете...

(Y) - В Вилладже есть местечки, которые прекрасньл.

- Вне Вилладжа да. Конечно же, Вы не захотите утратить их. Но где-либо еще, знаете ли, они все похожи друг на друга - хромированные и черные стулья...

- Ивсе эти картины и так далее...

- Да, очевидно, это не те местечки, где хотят, чтобы вы задержались...»

В предваряющей неформальную беседу реплике интервьюер сообщает, что частные кафе в Нью-Йорке являются безликими. В следующем диалогическом ходе респондент, реализуя уступку, признает, что предыдущее суждение интервьюера является частично истинным: он выражает согласие с тем, что безликими предстают те частные кафе, которые находятся вне района Гринвич Вилладж. В то же время респондент поддерживает мысль о том, что в другом отношении инициальное суждение интервьюера является ложным: уютными в Гринвич Вилладж являются не только частные кафе.

Зарождающаяся в неформальном общении контрастность смысловых позиций интервьюера и респондента затмевается риторическими уступительными отношениями, а потому в спонтанном взаимодействии собеседников создаются условия для неконфликтного достижения общего мнения. Базовая модель реализации риторических отношений уступки и ее варианты исходно предполагают равный удельный вес двух потенциально несовместимых точек зрения в плане обсуждаемых событий, явлений, фактов, а также объектов, обнаруживаемых в этих событиях, явлениях и фактах. В частности, ограничение действенности предшествующей пропозиции на уровне отдельного речевогохода рассматривается нами как своеобразная стратегия, нацеленная на предотвращение нежелательного комментария со стороны интервьюера. Данная функция уступительных отношений актуализуется также для получения согласия интервьюера с точкой зрения, представленной респондентом.

Подтекстный смысл базовой модели выявляет семантическое содержание информации о «Я» респондента в связи с эмоциональным переживанием некогда приобретенного жизненного опыта, смещает фокус внимания в спонтанном взаимодействии в плоскость контекста сообщения о данном опыте. Уступка, выражаемая респондентом в пользу мнения интервьюера, дает ему возможность сообщить о том, что запомнилось им в плане обсуждаемого события или факта. Прагматическая функция риторических отношений уступки в подобном диалогическом контексте заключается в обеспечении детализации обсуждаемого события с точки зрения субъективной перспективы, отличной от перспективы интервьюера. Сообщение о запомнившемся событии материализуется как интенсивное аффективное переживание, ставящее перед респондентом проблему такой репрезентации события, которая позволила бы преодолеть аффект и установить дистанцию в отношении источника запомнившегося. С опорой на риторические отношения уступки респондент воспринимает «себя прошлого» как постороннего. Респондент вспоминает не только себя, но и то, каким образом он обозревал объективную реальность прежде, т.е. репрезентирует не только объективный мир, но и свой способ видения этого мира.Ср.:

"- I'd like to say that I really think a lot of people were sincerely there, just to make the option known that it was still time to negotiate, and we didn't need to start the bombing... (X) and I hate to see everybody get a bad name for that, and you say that's what makes it New York.

$\left(X^{\prime}\right)$ - Yes.

(Y) But it is a shame and it unfortunately the fact that there are more people like you than the rest..." (LondonPaper, 2014, № 31, p. 12).

«- Я хотел бы сказать, что я действительно много думаю о том, что люди были искренними там, просто предоставив альтернативу, а именно возможность договориться; и не было необходимости в том, чтобы мы начали бомбардировку... (X) и мне совсем не нравится, когда все плохо отзываются об этом, и Вы говорите, что в этом и состоит суть Нью-Йорка.

$\left(X^{\prime}\right)-Д а$.

(Y) Но это позор и, к несчастью, факт того, что становится больше людей таких, как Вы, отличных от остальных...»

В анализируемом отрывке из неформальной беседы интервьюер выражает мнение, согласно которому некоторые участники демонстрации желали, чтобы их смысловая позиция была услышана (а именно 
бомбардировка началась слишком рано, до того, как все возможности переговоров были исчерпаны). Инициатор неформальной беседы также добавляет, что свобода самовыражения, реализуемая в мирной форме, предстает фундаментальным правом. Респондент сначала соглашается с выдвинутым мнением интервьюера $\left(\left(X^{\prime}\right)\right.$ - Yes.), но затем переходит к негативной оценке произошедшего (обсуждаемое событие оценивается как фактический позор), которая оказывается потенциально несовместимой с позитивным освещением права свободы самовыражения, представленным интервьюером в исходной реплике.

ЗАКЛЮЧЕНИЕ. Неформальное интервью занимает сильную позицию в популярных изданиях, отражающих текущие тенденции в сфере моды, кино, спорта, повседневности вообще. Взаимно вовлекаясь в неформальное интервью, собеседники фактически ориентируются на образ читателя, для которого это интервью и производится. Ориентация на данный образ в известной степени предопределяет частотность выражения риторических отношений уступки в неформальном интервью. В непринужденном повседневном общении подобные ограничения отсутствуют, сферу интересов собеседников составляет иллокутивное состязательство, стремление решить собственные неречевые задачи.

Несходные смысловые позиции собеседников манифестируются такими компонентами модели реализации риторических отношений уступки, как $\mathbf{( X )}$ и $(\mathbf{Y})$, при этом в речевом ходе $\left(\mathbf{X}^{\prime}\right)$ выражается согласие реагирующего участника интервью с предварительно инициированной точкой зрения (X), которая принадлежит другому собеседнику, уступка в пользу его смысловой позиции. Выраженная уступка, в свою очередь, становится основанием для представления альтернативного мнения (Y), отражающего иной взгляд на обсуждаемую проблему. При этом компоненты (X') и (Y) реализуютсяпреимущественно на уровне речевых ходов одного участника интервью.

Как показал наш анализ, компоненты модели $(\mathbf{X}),\left(\mathbf{X}^{\prime}\right)$ и $(\mathbf{Y})$ получают реализацию в языковых единицах разнообразной степени сложности: в отдельных словоформах, словосочетаниях, простых и сложных предложениях, которые, по сути дела, предстают как самостоятельные дискурсивные блоки, участвующие в формировании риторических отношений.

Вариативные возможности модели реализации риторических отношений уступки в рамках неформального интервью детерминируются равным участием журналиста и респондента в проектировании спонтанно порождаемого диалогического текста. Один из собеседников осуществляет уступку в пользу смысловой позиции другого собеседника, реализуя при этом потенциально контрастное суждение. В результате сглаживается полярность позиций участников интервью, осуществляется плавный переход к обсуждению других тем. Когнитивная природа потенциального контраста детерминируется способностью участников неформального интервью производить выводное знание из речевых шагов партнера по общению. Другими словами, компоненты обсуждаемой проблематики $(\mathbf{X})$ и $(\mathbf{Y})$ не воспринимаются собеседниками как исходно контрастирующие, а интерпретируются как таковые в рамках ситуационного контекста текущего диалогического взаимодействия.

\section{LIST OF REFERENCES}

Azarova, O.A. Kommunikativnye strategii i taktiki respondenta v angloyazychnom neformal'nom interv'yu [Tekst]: dis. ... kand.filol.nauk/ O.A.Azarova. - Rostov n/D., 2013. - 187 s.

Afanas'eva, I.V.Lingvo-ritoricheskie osobennosti angloyazychnogo interv'yu [Tekst]: dis. ... kand.filol.nauk/I.V.Afanas'eva. - SPb., 2010. - $221 \mathrm{~s}$.

Valgina, N.S. Teoriya teksta [Tekst] / N.S.Valgina. - M.: Logos, 2003. - 280 s.

Vartanova, N.G. Strukturno-semanticheskie i funkcional'nye osobennosti zhanra reklamnogo interv'yu v russkih i francuzskih SMI

[Tekst]: dis. ... kand.filol.nauk/ N.G.Vartanova. - Rostov n/D, 2006. - 168 s.

Karasik, V.I.Rechevaya kommunikaciya: diskursivnyy aspekt [Tekst] / V.I.Karasik // Grani poznaniya: elektronnyy nauchnoobrazovatel'nyy zhurnal VGSPU. - 2013. - № 1 (21). - S. 23-33.

Klemenova, E.N. Kvantor. Smysl. Tekst. Interpretaciya [Tekst] / E.N.Klemenova. - M.: FLINTA: Nauka, 2017. - 168 s.

Plotnikova, O.A. Strategii kontrolya dialogicheskogo vzaimodeystviya v interv'yu [Tekst] / O.A.Plotnikova. - Omsk, $2007 .-180 \mathrm{~s}$.

Sossyur, F. de. Kurs obschey lingvistiki[Tekst]/ F. de Sossyur. - Ekaterinburg: Izd-vo Ural'sk.un-ta, 1999. - $432 \mathrm{~s}$.

Homskiy, N. Aspekty teorii sintaksisa [Tekst] /N.Homskiy. - M.: Izd-vo Mosk. un-ta, 1972. - 260 s. Shishkina, T.S.

Pragmaticheskie osobennosti konstativnogo rechevogo akta $v$ funkcii iniciiruyuschey repliki neformal'nogo interv'yu [Tekst]: avtoref. dis. ... kand. filol. nauk / T.S.Shishkina. - Rostov n/D, 2010. - $18 \mathrm{~s}$.

Mann, W.C. Rhetorical Structure Theory: Toward a Functional Theory of Text Organization [Text] / W.C. Mann, S.A. Thompson. Amsterdam: John Benjamins, 1988. - Vol. 8 (3). -P. 243 - 281.

Strauss, P. -M. Proactive Spoken Dialogue Interaction in Multy-Party Environments [Text] / P.-M. Strauss, W. Minker. - N.Y.; L.: Springer, 2010. $-180 \mathrm{p}$.

\section{For citation:}

Klemenova E. N., Kovalchuk N. V. (2019) ON THE DISCURSIVE-PRAGMATIC PROPERTIES OF CONCESSION IN INFORMAL INTERVIEW // International Scientific-Pedagogical Organization of Philologists “ WEST-EAST ” (ISPOP). Scientific Journal WEST-EAST. Vol 2/1 N1 (October, 2019). pp. 76-80. doi:

Для цитирования:

Клеменова Е. Н., Ковальчук Н. В. (2019) О ДИСКУРСИВНО-ПРАГМАТИЧЕСКИХ СВОЙСТВАХ УСТУПКИ В НЕФОРМАЛЬНОМ ИНТЕРВЬЮ // Internationa 1Scientific-Pedagogical Organization of Philologists “ WEST-EAST” (ISPOР) . Scientific Journal WEST-EAST. Vol 1/1 N1 (October, 2019). C. 75-79. doi: 
Information about the authors: Elena Nikolaevna Klemenova - Doctor of Philological Sciences, Professor, Department of Journalism, Rostov State University of Economics (RINE),

Russia, Rostov on Don

klemenova@yandex.ru

Nadezhda Vladimirovna Kovalchuk - PhD, Associate Professor, Department of Foreign Languages, Don State Technical

University, Russia, Rostov on Don

nadezhda_kovalchuk_2012@mail.ru

Информация об авторах:Елена Николаевна Клеменова -доктор филологических наук, профессор кафедры

журналистики, Ростовский государственный университет экономики Ростов-на Дону, Россия

klemenova@yandex.ru

Надежда Владимировна Ковальчук - кандидат филологических наук, доцент кафедры иностранных языков, Донской государственный технический университет

nadezhda_kovalchuk_2012@mail.ru

Manuscript received: 05/10/2019 Accepted for publication: 09/20/2019

DOI:

\title{
LANGUAGE NORMS AND USAGE IN UKRAINIAN MASS MEDIA
}

\author{
Svitlana Korotkova \\ PhD, Associate Professor \\ National Technical University "Dniprovska Polytechnica" \\ (Dnepr, Ukraine) \\ e-mail: sveta_korotkova@i.ua \\ Olena Polovynko \\ PhD, Associate Professor \\ University of Strasbourg \\ (Strasbourg, France) \\ e-mail: polovynko@unistra.fr
}

\begin{abstract}
This research traces the evolution of the norms of the Ukrainian and Russian languagesand their usage in modern Ukrainian media discourse. In linguistic literature widespread understanding of the norm (tradition of the use of linguistic units) and narrow (result of purposeful language codification)are extended. The process of standardization of Ukrainian and Russian languages took place in different ways. The national Ukrainian literary language belongs to the languages with an ancient tradition but its norms were not established until quite recently, having changed several times. Analysis of media discourse reveals that a high level of proficiency in the state language demonstrates a limited group of the country's population. As for the Russian language, while it does not lose its communicative power in many regions of Ukraine, in the speech of monolinguist Russophones there are errors and ukrainisms.The intermediate Ukrainian-Russian language varieties, surzhyk,holds a special position in the media and public performances. In general, the contemporary Ukrainian media discourse demonstrates non-compliance with legislative and academic requirementsbut reflects the complexity of the linguistic situation in Ukraine.
\end{abstract}

Keywords: language norm, language standardization (normalization), media discourse, Ukrainian language, Russian language, surzhyk

НОРМЫ И ФУНКЦИОНИРОВАНИЕ ЯЗЫКОВ В УКРАИНСКИХ МАСС-МЕДИА

\author{
Светлана Витальевна Короткова \\ Кандидат филологических наук, доцент \\ Национальный ТУ «Днепровская политехника», \\ (Днепр, Украина) \\ e-mail: sveta_korotkova@,i.ua
}

Елена Алексеевна Половинко

Кандидат филологических наук, ассоциированный профессор

Страсбургский университет,

(Страсбург, Франция)

e-mail: polovynko@unistra.fr

Аннотация: В данном исследованииособое внимание уделено истории становления норм украинского и русского языков и функционированиюязыковых систем в современном украинском медиадискурсе. В лингвистической литературе встречается 